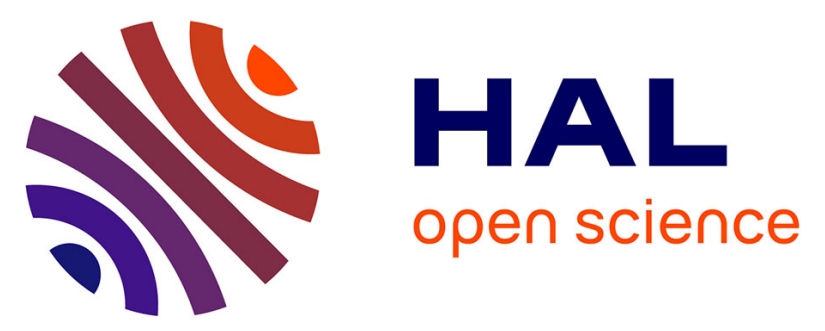

\title{
Evaluation of a micro-spectrometer for the real-time assessment of liver graft with mild-to-moderate macrosteatosis: A proof of concept study
}

N. Golse, Cyril Cossé, M. A. Allard, A. Laurenzi, M. Tedeschi, N. Guglielmo, E. Fernandez-Sevilla, M. Robert, B. Trechot, D. Pietrasz, et al.

\section{To cite this version:}

N. Golse, Cyril Cossé, M. A. Allard, A. Laurenzi, M. Tedeschi, et al.. Evaluation of a microspectrometer for the real-time assessment of liver graft with mild-to-moderate macrosteatosis: A proof of concept study. J Hepatol, 2019, 70 (3), pp.423-430. 10.1016/j.jhep.2018.10.034 . hal-02195253

\section{HAL Id: hal-02195253 \\ https://hal.science/hal-02195253}

Submitted on 22 Oct 2021

HAL is a multi-disciplinary open access archive for the deposit and dissemination of scientific research documents, whether they are published or not. The documents may come from teaching and research institutions in France or abroad, or from public or private research centers.
L'archive ouverte pluridisciplinaire HAL, est destinée au dépôt et à la diffusion de documents scientifiques de niveau recherche, publiés ou non, émanant des établissements d'enseignement et de recherche français ou étrangers, des laboratoires publics ou privés.

\section{()ㅜ(1)}

Distributed under a Creative Commons Attribution - NonCommerciall 4.0 International 


\section{Evaluation of a micro-spectrometer for the real-time assessment of liver graft mild-to-} moderate macrosteatosis: a proof of concept study

N. Golse ${ }^{1,2,3,4}, \mathrm{MD}$, C. Cosse ${ }^{5}, \mathrm{MD}$, M.-A. Allard ${ }^{1}, \mathrm{MD}$, A. Laurenzi ${ }^{1}, \mathrm{MD}, \mathrm{M}$. Tedeschi $^{1}$, MD, N. Guglielmo ${ }^{1}, \mathrm{MD}$, E. Fernandez-Sevilla ${ }^{1}, \mathrm{MD}, \mathrm{PhD}, \mathrm{M}$. Robert $^{6}, \mathrm{MD}, \mathrm{PhD}$,

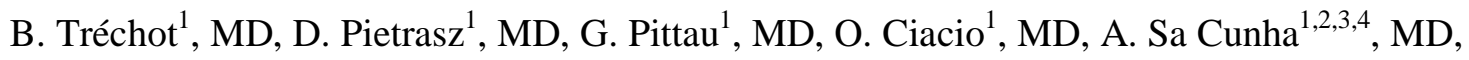
D. Castaing ${ }^{1,2,3,4}$, MD, D. Cherqui ${ }^{1,2,3,4}$, MD PhD, R. Adam ${ }^{1,2,7,8}$, MD PhD,

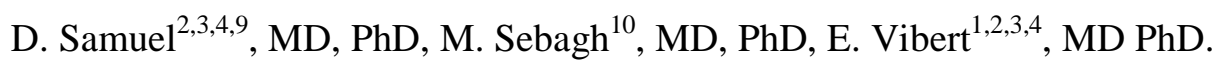

\section{$\underline{\text { From }}$}

${ }^{1}$ Department of Surgery, Paul-Brousse Hospital Assistance Publique Hôpitaux de Paris, Centre Hépato-Biliaire, Villejuif, 94800, France

${ }^{2}$ DHU Hepatinov, Villejuif, 94800, France

${ }^{3}$ INSERM, Unit 1193, Villejuif, 94800, France

${ }^{4}$ Univ Paris-Sud, UMR-S 1193, Villejuif, 94800, France

${ }^{5}$ Faculty of Medicine Paris V, Paris, 75020, France

${ }^{6}$ Department of General Surgery and Bariatric Surgery, Edouard Herriot Hospital, Hospices Civils de Lyon-Claude Bernard Lyon 1 University,

${ }^{7}$ INSERM, Unit 776, Villejuif, F-94800, France

${ }^{8}$ Univ Paris-Sud, UMR-S 776, Villejuif, 94800, France

${ }^{9}$ Department of Hepatology, Paul-Brousse Hospital Assistance Publique Hôpitaux de Paris, Centre Hépato-Biliaire, Villejuif, 94800, France

${ }^{10}$ Department of Pathology, Paul-Brousse Hospital Assistance Publique Hôpitaux de Paris, Centre Hépato-Biliaire, Villejuif, 94800, France

\section{Results presented as oral communication at the :}


- $13^{\text {rd }}$ Francophone HPB \& Digestive Surgery Congress, November 2017, Marne la Vallée,

France.

- Journées Francophones of Hepato-Gastroenterology and Digestive Oncology (JFHOD 2018), March 2018, Paris, France

- European Association for the Study of the Liver (EASL) congress, April 2018, Paris, France - International Liver Transplantation Society (ILTS) congress, May 2018, Lisbon, Portugal

\section{DISCLOSURE}

The authors of this manuscript have no conflicts of interest to disclose. 
Category: Original article

\section{Correspondence and reprint requests:}

Dr Nicolas Golse, Centre Hépato-Biliaire, Hôpital Paul Brousse

12 Avenue Paul Vaillant Couturier 94804 Villejuif Cedex

nicolasgolse@me.com

Tel.: $0033145593036 \quad$ Fax:0033145593857

Running title: A reliable and low-cost technique

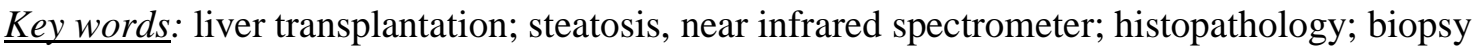

\section{Abbreviations:}

CAP: controlled attenuation parameter

F-TIR: Fourier-transform infrared spectroscopy

LS: liver steatosis

LT: liver transplantation

$\mathrm{mS}$ : microsteatosis

MS: macrosteatosis

OR: operating room

PSM: pocket sized micro-spectrometer

$\mathrm{R} 2$ : coefficient of determination

S1: stage 1

S2: stage 2

SD: standard deviation 
2 Tables +5 Figures

Words count $=5503(5974$ for the previous version $)$

\section{AUTHOR'S CONTRIBUTION:}

Golse: Writing paper, design and data collection manager

Cosse: Statistical analysis

Golse, Allard, Laurenzi, Tedeschi, Pietrasz, Guglielmo, Fernandez-Sevilla, Robert, Tréchot, Pittau, Ciacio: Data acquisition during procurements. Reviewed the manuscript.

Sa Cunha, Castaing, Cherqui, Adam: performed surgeries, study supervision

Sebagh: Pathological analysis

Samuel: supervision and correction of the manuscript

Vibert: Supervisor of the work, manuscript correction 


\section{ABSTRACT}

Background: Liver macrosteatosis (MS) is a major predictor of graft dysfunction after transplantation. However, frozen section techniques to quantify steatosis are often unavailable in the context of procurements, and the findings of preoperative imaging techniques correlate poorly with those of permanent sections, so that the surgeon is ultimately responsible for the decision. Our aim was to assess the accuracy of a non-invasive pocket spectrometer (PSM) for the extemporaneous estimation of MS.

Methods: We prospectively evaluated a commercial PSM by scanning the liver capsule. A double pathological quantification of MS was performed on permanent sections. Initial calibration (training cohort) was performed on 35 livers $(\mathrm{MS} \leq 60 \%)$ and an algorithm was created to correlate the estimated (PSM) and known (pathological) MS values. A second assessment (validation cohort) was then performed on 154 grafts.

Results: Our algorithm achieved a coefficient of determination $\mathrm{R} 2=0.81$. Its validation on the second cohort demonstrated a Lin's concordance coefficient of 0.78 . Accuracy reached $0.91 \%$, with reproducibility of $86.3 \%$. The sensitivity, specificity, positive and negative predictive values for $\mathrm{MS} \geq 30 \%$ were $66.7 \%, 100 \%, 100 \%$ and $98 \%$, respectively. The PSM could predict the absence $(<30 \%) /$ presence $(\geq 30 \%)$ of MS with a kappa coefficient of 0.79 . Neither graft weight nor height, donor body mass index nor the CT-scan liver-to-spleen attenuation ratio could accurately predict MS.

Conclusion: We demonstrated that a PSM can reliably and reproducibly assess mild-tomoderate MS. Its low cost and the immediacy of results may offer considerable added-value decision support. This tool could avoid the detrimental and prolonged ischaemia required by the pathological examination of (potentially) marginal grafts. This device now needs to be assessed in the context of a large-scale multicentre study. 


\section{LAY SUMMARY}

The macro-vacuolar liver steatosis is a major prognostic factor for outcomes after liver transplantation. However, it is often difficult for logistical reasons to get this estimation during a procurement. In this perspective, we developed an algorithm for a commercial, portable and affordable spectrometer to accurately estimate this content in a real-time fashion. This device could be of great interest for clinical decision-making to accept or discard a potential human liver graft. 


\section{INTRODUCTION}

The current organ shortage has led most liver transplant teams to use marginal grafts that modify the benefit-risk ratio for recipients and imposes a heavy responsibility on the surgical teams (1).

Liver steatosis (LS) remains a major concern in liver transplantation (LT) because nonalcoholic fatty liver disease can affect up to $30 \%$ of individuals (potential donors) in western countries, as confirmed by the reported incidence of LS during procurement (2). LS involves two types of steatosis: macrosteatosis (MS) characterised by a single, bulky fat vacuole in hepatocytes that displaces the nucleus to the edge of the cell, and microsteatosis $(\mathrm{mS})$ when the cytoplasm of hepatocytes contains tiny lipid vesicles without nuclear dislocation. In almost all reports, only MS has negatively impacted outcomes after LT, while the low or negligible impact of $\mathrm{mS}$ is accepted (3-6). If steatotic (MS) grafts are used, there is general consensus regarding a higher incidence of primary non function and biliary complications, increased costs and longer stays in hospital, associated with poorer patient and graft survivals (7-11). These grafts are more susceptible to cold ischemia (12), which explains why there is a growing body of literature on the normothermic preservation of fatty livers in order to limit ischemia-reperfusion disorders and induce "defatting" $(1,13,14)$.

The principal issue regarding LS in the LT setting is the diagnosis and quantification of MS. There is a global agreement that mild MS $(<30 \%)$ causes little or no graft injury, while a moderate $(30-60 \%)$ or high $(>60 \%)$ degree of $\mathrm{MS}$ constitute a significantly higher risk $(7,9,15,16)$. However, the preoperative diagnosis of MS remains a challenge. Many noninvasive techniques have been described but their accuracy remains a matter of debate (17): 1/ ultrasonography is able to detect the presence of severe steatosis but remains a little accurate (non-quantitative) and operator-dependent procedure (18); 2/ despite many liver attenuation indices published, a diagnosis of mild to moderate LS remains insufficient using a CT scan 
$(19,20) ; 3 /$ the magnetic resonance spectroscopy examinations are accurate but costly and unavailable before organ retrieval $(21,22)$; 4 / the use of percutaneous ultrasonic controlled attenuation parameter (CAP) is a promising technique but we are still awaiting cheap machines with reliable and consensual cut-off values for the distinction of moderate/high LS content (23).

Practically, the final decision often relies on the macroscopic appearance of the graft, even though it is well known that an evaluation performed by the surgeon is poorly correlated to pathological estimations $(24,25)$. It must also be remembered that the results of frozen sections are not aligned with those of permanent sections, with MS being underestimated in $75 \%$ cases (26). Moreover, a frozen section is not always technically feasible (organisational issues) as its accuracy depends on the hospital where the retrieval is performed (often peripheral), and it frequently results in a longer cold ischemia time if the biopsy needs to be transferred from the hospital where the procurement takes place to the transplant centre.

Recent publications in the LT setting on infrared spectroscopy have produced some very promising results as it enabled an accurate quantification of LS (27-29). Spectroscopy is based on determining the absorption of infrared light due to resonance with vibrational motions of functional molecular groups. Clinical studies have already demonstrated the feasibility and reliability of this concept $(30,31)$. However, the outstanding issue is that this technique requires expensive and non-transportable equipment. Until now, clinical experiments required contact between a probe and the liver (introduction of a needle into the organ), this being an invasive technique with theoretical complications.

We aimed to prospectively evaluate the feasibility and accuracy of a new "contact-free" portable pocket spectrometer to quantify MS in liver grafts. The main goal of this study was to correlate the estimated MS with the one obtained from the pathologists (continuous and categorical correlations). 


\section{MATERIALS AND METHODS}

\section{Spectrometer}

We used a pocket-sized micro-spectrometer (PSM) commercialised by SCIO - Consumer Physics (http://www.consumerphysics.com). This near infrared (700-1100nm) PSM is granted $\mathrm{CE}$ and FCC labelling and is sold for both the general public and professionals. It is provided with an application that can quantify the composition of foods, as well as estimating body fat levels and identifying analgesics. At present it is mainly used by professionals to test animal feeds, grains or raw materials, in manufacturing and in the pharmaceutical industry. For these purposes, it requires specific applications and algorithms which can test the desired variable and are developed by the users themselves after the creation of a dataset and models. To this end, a correlation between the spectra and known quantifications of the studied variable is necessary and obtained by creating a specific algorithm.

The PSM is portable, small $(68 \times 40 \mathrm{~mm})$, light (35 grams), rapid (scan time $<4$ seconds) and affordable (Fig 1). It delivers real-time results and requires three components: $1 /$ the SCIO spectrometer itself, 2/ a smartphone (iOS or Android) connected by Bluetooth to operate the SCIO application, and 3/ a secured internet connection to the SCIO Cloud in order to build a database (stage 1) and then query the pre-established algorithm (stage 2).

\section{Rationale for the present study (stage 0 )}

Before starting this study, our first aim was to determine whether the application supplied (SCIO application - not developed for human organ assessment) could be used to quantify the fat content in human liver. Between September 2016 and November 2016, we tested several modules of the app ("dairy", "raw fat", "raw poultry", "raw pork", "raw fish" and "other raw meats") on 25 livers. Compared with the definitive pathological results, none of the modules was able to quantify micro-, macro- or total steatosis (data not shown) and the values obtained 
by the PSM never correlated with the findings of pathological analysis. We concluded that in order to obtain an accurate PSM, we would have to create our own algorithm, calibrated on human livers.

\section{Design of the study (Flow chart, Fig 2)}

This study was performed in a tertiary centre with extensive experience of LT (>150 LT per year). Because the PSM is a new diagnostic tool requiring specific calibration, this study was therefore carried out in two stages:

1/ Between December 2016 and February 2017, the first stage (S1, training cohort) enabled us to define the optimum conditions of use. We developed an algorithm that could determine the MS content from the liver scans.

2/ Between March 2017 and August 2018, we tested the algorithm (created during stage 1) on a new cohort of patients (validation cohort), mainly in LT setting. This second stage (S2) was necessary to evaluate the accuracy of our algorithm.

\section{Study population}

During S1, we included different categories of patients and scanned various types of livers, namely grafts during procurement (deceased donors only) or after implantation into recipients, and also organs obtained during elective liver surgery (benign or malignant tumours). In the LT setting, no specific consent could be obtained because only deceased donor LT procedures were included in this study. However, livers from donors whose families refused the conduct of research were not scanned (information systematically given by the French agency regulating the transplantations). In the context of elective liver surgery all patients gave their informed and signed consent for medical research on their liver specimens. This study was conducted in accordance with the Declaration of Helsinki and the International Conference on Harmonization of Good Clinical Practices. 
No clinical decisions were based on the PSM findings in the context of this exploratory study.

Exclusion criteria defined at the end of S1: age <18 years old; liver with underlying pathology: fibrosis $\geq \mathrm{F} 2$ Metavir score (definitive pathological assessment); cholestasis; patient having received chemotherapy; livers with malignant lesions. In fact, cholestasis (yellow colour), sinusoidal obstruction syndrome (blue colour) and fibrosis could have biased the spectral analysis. These criteria were established in accordance with our ultimate goal to assess the steatosis of liver grafts (not in an elective surgery setting) and for this purpose we excluded all clearly pathological organs (namely cirrhotic, cholestatic and post-chemotherapy livers).

\section{Liver scanning protocol}

Surgeons (juniors and seniors operators) belonging to the Paul Brousse team performed all the scans. The median time to scan the livers was less than 2 minutes, and the impact on the surgical procedure (stop of the procedure) was almost negligible.

Operating conditions: the scan was performed at a distance $\leq 1 \mathrm{~cm}$ from the liver capsule, in a well-lit operating room (OR) with the surgical light switched off. At least three scans per liver were performed on the left lobe, near to the site of the surgical biopsy. All scans were performed during the beating heart phase, at $37^{\circ} \mathrm{C}$.

All the data of this study were anonymized before sending to the secured server.

\section{Pathological analysis}

All the grafts analysed underwent a surgical biopsy in the left lobe (no needle biopsy), before clamping and/or after revascularisation. In the non-LT group, the non-tumour 
parenchyma was scanned and analysed for steatosis while the tumour content was not assessed for this study.

The samples were fixed in alcohol-formalin-acetic acid, embedded in paraffin and stained with standard haematoxylin eosin safran and picrosirius stain. The samples were blindly analysed by the team of the pathological unit. Secondarily, a single experienced pathologist (M. S.) reviewed the samples, specifying the $\mathrm{mS}$ and MS content. In case of discrepancy, we noted the mean values between operators.

\section{Spectral analysis}

Spectral analysis was performed online using the developer's website $\left(\mathrm{SCIO}^{\circledR}\right)$ in order to determine a correlation between known and estimated values. The only parameters modulated were: 1/ the pre-processing method: processed, normalised, processed and normalised, or $(\log (\mathrm{R}))$ " + normalised, and $2 /$ the wavelength filtering. The analytical algorithm was not communicated but the performance of the models was shown by means of two indicators: the coefficient of determination (R2: measuring the degree of replication by the model of observed outcomes) and the root-mean-square deviation (RMSE: sample standard deviation of the differences between predicted values and observed values). A perfect model would have values of $2=1$ and $\mathrm{RMSE}=0$. In the sections below, the estimation of MS by the algorithm is referred to as the "calculated macrosteatosis".

\section{Sample size calculation}

To obtain a correlation ( $\rho \mathrm{c}$ ) of at least 0.35 (i.e. at least a fair correlation) between the two assessments of macrosteatosis, and based on an alpha risk of $5 \%$ and a power of $90 \%$, the calculated sample size was of (at least) 80. We enlarged this required cohort to obtain a higher proportion of steatotic specimens. 


\section{Statistical analysis}

Epidemiological, pathological and clinical data were all collected by one operator (NG). Quantitative continuous variables were expressed as mean \pm standard deviation (SD), while qualitative variables were expressed as numbers (n) and percentages (\%).

Correlations were presented as scatterplots generated using Lin's concordance correlation coefficient $(\rho \mathrm{c})$. These scatterplots were obtained by averaging 1,000 bootstrap samples (sampling with replacements) from the original population $(n=154)$. This method was able to limit the impact of outliers and enable more robust representations.

To provide a clearer information, the Kappa coefficient $(\kappa)$ was also calculated to assess the consistency between pathological MS (gold standard) and calculated MS. To achieve this second analysis, the MS values were placed within two ranges $(<30, \geq 30)$.

Overall uncertainty was presented as accuracy and systematic bias with a 95\% confidence interval. The reproducibility represented the variability between measures obtained from the same sample with the same method; it was an approximation of the R2.

The systematic bias corresponded to the systematic error that was introduced in all calculations, i.e. the precision of the values we obtained.

The results of this series were presented according to the STARD guidelines. P values $\leq$ 0.05 were considered to be statistically significant. All statistical analyses were performed using PASW software, version 22 (SPSS Inc., Chicago, Ill). 


\section{RESULTS}

\section{Stage 1: Calibration = creation of the algorithm}

During the first step of the methodology, we included 67 livers (270 scans) from donors $(n=18)$, recipients $(n=25)$ and patients undergoing elective liver surgery $(n=24)$. The characteristics of the population are shown in Table 1.

For the whole group, we failed to create a reliable algorithm that could predict liver steatosis (Figs 3A). Whatever the pre-processing method and wavelength analysed, we were not able to achieve a $\mathrm{R} 2$ value $>0.4$.

We applied selection criteria (proposed after iterative approach) on this cohort and finally analysed only 35 livers (138 scans). Known MS values ranged from 0\% to 60\%, while those for $\mathrm{mS}$ were between $0 \%$ and $50 \%$. By filtering the spectral wavelength between $895 \mathrm{~nm}$ and $945 \mathrm{~nm}$, we were able to create an algorithm, and this model predicted MS with R2 $=0.811$ and $\mathrm{RMSE}=5.26($ Fig $3 \mathrm{~B}$ and 4$)$.

However, we failed to create an accurate model that could predict $\mathrm{mS}$ or global steatosis.

\section{Stage 2: Validation of the pre-established algorithm}

The algorithm obtained during stage 1 was then tested on a new prospective cohort of organs ( $\mathrm{n}=154)$. We performed $4.1 \pm 1$ scans / liver analysed. Nine livers reached a definitive $\mathrm{MS} \geq 30 \%$.

Lin's correlation between the estimated MS values (using PSM) and known MS values was $0.78(0.73-0.83 ; \mathrm{p}<0.0001)$. The accuracy of our algorithm was of $0.91 \%(0.84-0.98)$; its reproducibility was $86.3 \%$ with a systematic bias of $1.12 \%(0.24-1.99)$.

After applying the MS ranges $(<30 \%$; $\geq 30 \%)$, the kappa agreement index between the PSM and the pathological results was 0.79 . The sensitivity, specificity, positive and negative predictive values for MS $\geq 30 \%$ were $66.7 \%, 100 \%, 100 \%$ and $98 \%$, respectively. 
As shown in Table 2 and Fig 5, none of the potential preoperative predictors of MS available for acceptance decision (body mass index, liver height, liver-to-spleen attenuation ratio) achieved a reliable correlation with the pathological results because the correlation was $<0.3$. Although statistically significant $(\mathrm{p}<0.05)$, graft weight and BMI generated a poor correlation with the MS.

In the validation cohort, 10 patients presented at definitive pathological analysis a $\mathrm{mS} \geq$ $30 \%$. Among these patients, the mean (definitive) MS was of $5.1 \pm 4.3 \%$ and the maximum MS was of $10 \%$. All the MS estimations by the PSM were $<17 \%$, meaning that the algorithm was able to differentiate the MS from $\mathrm{mS}$.

During this validation stage, two (junior) surgeons refused a graft $(n=2)$ because of their steatotic gross appearance. No frozen sections were performed because no pathologist was available during the night and the hospital was too distant from our transplant centre to send a biopsy specimen. These procurements were stopped. In both cases, the permanent section analysis contradicted the visual fat estimation, and showed 5\% MS only. The PSM also confirmed the low-fat content of these refused grafts (respectively 3\% and 5\% MS). If the surgeons had taken account of the PSM values into their decision algorithm, these two grafts would have been transplanted.

\section{Performance of the frozen section analysis versus PSM estimation}

During the study time, a frozen section analysis was only performed on seven donor grafts for MS and fibrosis assessment. The Lin's correlation between the frozen section and pathological definitive assessments was of 0.59 , whereas it was of 0.73 between the PSM and definitive pathological assessment (MS analysis). The median difference between frozen section and definitive analysis was of $10.8 \% \pm 16$, whereas it was of $6.5 \% \pm 9$ for the PSM $(\mathrm{p}=0.43)$. 


\section{DISCUSSION}

\section{Statement of principal findings}

Using a commercial PSM for macrosteatosis quantification, we created our own algorithm that could correlate the liver spectra with the definitive pathological assessment, and we confirmed its accuracy on a second independent cohort. The good coefficient of correlation (0.78) between the estimated and known MS confirmed the relevance of our algorithm. The specificity and negative predictive value were particularly high, thus confirming that the actual algorithm is able to determine with a great confidence the low steatotic livers. Moreover, we did not observe any false positive cases, meaning that the operator should be very vigilant before accepting a graft in case of PSM value $\geq 30 \%$. The PSM was more accurate than frozen section to estimate MS content.

This non-invasive device, which is both transportable and affordable, could become part of the standard surgical equipment necessary during liver procurement and, with the view of clinical use, the PSM will provide the raw MS percentage and the clinician will be able to accept or not the organ (multiparametric decision).

\section{Strengths and weaknesses of the study}

The principal strength of this study was its prospective design involving two independent cohorts (one for calibration, one for validation). Thanks to a large sample size, we were able to define the optimum conditions for use, and we obtained a highly accurate algorithm. Another advantage of this device is the potential upgradability of the algorithm during the coming months/years, when we will have included hundreds of patients.

However, this study had certain limitations. First, we did not scan any livers with MS over $60 \%$. This was a surprising finding, mainly explained by the fact that the 2 livers rejected because MS $>60 \%$ (visual assessment confirmed at definitive pathology) were not scanned due to the absence of network during procurement. This limits the scope of our algorithm 
because we cannot know if such a high fat content might have been assessed correctly by the PSM. One might argue that such steatotic livers do not present difficulties for macroscopic assessment and the PSM would probably have been of no added-value in such obvious cases. However, in order to achieve a rigorous evaluation, it will be necessary to study such grafts. It is worth noting that three patients had a BMI over $40 \mathrm{~kg} / \mathrm{m}^{2}\left(\max : 53 \mathrm{~kg} / \mathrm{m}^{2}\right.$ ) but none of them presented with MS over 15\% (range: [5-15\%]). This confirms the lack of correlation between BMI and MS. This low incidence of highly steatotic grafts could be explained because a surgical team is not generally dispatched for procurement when a highly steatotic liver is suspected. This limitation will be avoided in any future prospective and multicentric study when all grafts will be scanned, whether the organ is transplanted or not.

Because of the high prevalence of livers with low/intermediate fat content, the most reasonable conclusion to be drawn from our study is that the PSM never overestimates the MS of "good livers", and probably does not underestimate high values for "marginal livers". This means that use of the PSM will not cause the incorrect refusal of acceptable grafts. We have to confirm these promising results.

Secondly, neither $\mathrm{mS}$ nor global steatosis could be predicted by the PSM. In fact, our algorithm was exclusively calibrated to quantify MS.

Another limitation was the use of pathological assessment when calibrating our PSM. It would probably have been more accurate to use Fourier-transform infrared spectroscopy (FTIR) or an automated software $(32,33)$, even though these costly techniques are not yet established as the gold standard and necessitate specific equipment. More importantly, F-TIR requires preparation of the sample that is not appropriate in routine practice and large data collection. We are aware of the potential biases of pathological analysis, even for expert pathologists (34). For this reason, all the samples were analysed a second time by a single blinded operator (M.S.) and we reached an excellent inter-observer reproducibility. 
The lack of external validation could also appear as a strong limitation of our study. In that aim, we will soon implement a prospective multicentric study to validate (or improve if required) our algorithm. The last limitation of this device that has prevailed until now is the need for a GSM network (or WIFI) while scanning the liver in order to access the online algorithm. For this reason, $40 \%$ of the procurements performed during the study were not scanned, thus justifying a scan in the recipients. With the application that we are currently developing for the future, it will be possible to scan offline and then transmit the data as soon as a network is available.

\section{Interpretation with reference to other studies}

MS is a major concern in the LT and re-LT settings $(9,35)$ and its importance will increase as larger numbers of marginal grafts are used during the decades to come. To the best of our knowledge, no other tool is validated to quantify MS during procurement and there is unanimous agreement that imaging techniques cannot predict fat content (17). Biochemical data on the donors are also well known to correlate poorly with steatosis $(36,37)$, and complex scores/biomarkers have failed to differentiate moderate $v s$ severe steatosis $(38,39)$. Some authors recently reported their preliminary experience with diffuse reflectance spectroscopy in the OR $(30,31)$ but it is not cost efficient to equip every OR with such expensive devices. Interestingly, the correlation between pathological results and those of their device was 0.8 0.9 , which was as good as ours.

The assessment of MS in liver allograft biopsies using smartphone add-on lenses has recently been reported (40). This device does not appear to be as useful as our PSM because it requires a biopsy and a prepared slide ( $3 \mu \mathrm{m}$ tissue section). Another pilot-study has been published by a French group, assessing the performance of a smartphone camera to quantify 
the liver steatosis (41). Although promising, this work only evaluated 12 livers and the algorithm did not differentiate the $\mathrm{mS}$ from the MS.

When considering the potential advantages (or disadvantages) of PSM versus a liver biopsy (frozen or permanent section), account must be taken of the heterogeneity of steatosis within the liver. For this reason, and particularly in borderline cases, at least two biopsies (from two sites) need to be performed $(42,43)$. This increases the time required for interpretation and the risk of potential liver injury. Conversely, it is possible to scan many times both sides of the liver with the PSM and to obtain a MS estimation within just a few seconds.

Opinions vary considerably regarding the assessment and management of graft steatosis across countries and teams (44). No consensus has been reached as to a decision-support algorithm. We are proposing a new, user-friendly and accurate tool that could homogenise practices and enable systematic testing for MS in the OR. We believe that this device offers a new surgical technology that meets all requirements and could be adopted rapidly by the surgical community: there is high clinical demand, it is easy to use, inexpensive and compatible with current practices (no need to reorganise procedures) (45). Moreover, new policies have just been introduced in France regarding liver retrieval performed by urologists or a local team. In this case, the PSM could offer a valuable decision-support tool for these “non-HPB" surgeons.

In the near future, the role of PSM will be challenged by transient elastography and the CAP, a tool that can be used at the bedside and that provides estimates of both fibrosis (elastography) and steatosis (23). However, compared to the PSM, the CAP remains operatordependent and the cut-off points for different grades of steatosis remain ill defined (39).

In terms of perspectives regarding new uses for liver spectroscopy, we propose to use the PSM to help the clinician for the selection of marginal graft for normothermic preservation 
(46) and for the follow-up of defatting $(13,14)$, as it has been proved that steatosis decreases rapidly after perfusion (47). This might avoid the need for repeat biopsies and perfusion can be halted as soon as the MS percentage reaches the targeted cut-off value. 


\section{CONCLUSION}

In these preliminary results, we have shown that our algorithm, calibrated and validated on human livers, was well correlated to the pathological assessment for prediction of the MS content of liver grafts. This is the first tool specifically calibrated to assess graft MS, as other devices only estimate the global steatosis. Its low cost and the immediacy of its results may offer considerable value-added decision support and avoid the detrimental and prolonged ischemia required for pathological examination in the event of a (potentially) marginal graft. However, the PSM algorithm now needs to be evaluated (and upgraded in a more sensitive way) in a larger scale multicentric study so as to definitively validate its utility and its impact on the organisation of LT. 


\section{REFERENCES}

1. Graham JA, Guarrera JV. "Resuscitation" of marginal liver allografts for transplantation with machine perfusion technology. J Hepatol. 2014 Aug;61(2):418-31.

2. Angele MK, Rentsch M, Hartl WH, Wittmann B, Graeb C, Jauch K-W, et al. Effect of graft steatosis on liver function and organ survival after liver transplantation. Am J Surg. 2008 Feb;195(2):214-20.

3. Zamboni F, Franchello A, David E, Rocca G, Ricchiuti A, Lavezzo B, et al. Effect of macrovescicular steatosis and other donor and recipient characteristics on the outcome of liver transplantation. Clinical Transplantation. 2001 Feb;15(1):53-7.

4. Sharkey FE, Lytvak I, Prihoda TJ, Speeg KV, Washburn WK, Halff GA. High-grade microsteatosis and delay in hepatic function after orthotopic liver transplantation. Human Pathology. 2011 Sep;42(9):1337-42.

5. Salizzoni M, Franchello A, Zamboni F, Ricchiuti A, Cocchis D, Fop F, et al. Marginal grafts: finding the correct treatment for fatty livers. Transpl Int. 2003 Jul;16(7):486-93.

6. Fishbein TM, Fiel MI, Emre S, Cubukcu O, Guy SR, Schwartz ME, et al. Use of livers with microvesicular fat safely expands the donor pool. Transplantation. 1997 Jul 27;64(2):248-51.

7. Mccormack L, Dutkowski P, El-Badry AM, Clavien P-A. Liver transplantation using fatty livers: always feasible? J Hepatol. Elsevier; 2011 May;54(5):1055-62.

8. Dutkowski P, Schlegel A, Slankamenac K, Oberkofler CE, Adam R, Burroughs AK, et al. The use of fatty liver grafts in modern allocation systems: risk assessment by the balance of risk (BAR) score. Ann Surg. 2012 Nov;256(5):861-8-discussion868-9.

9. Adam R, Reynes M, Johann M, Morino M, Astarcioglu I, Kafetzis I, et al. The outcome of steatotic grafts in liver transplantation. Transplant Proc. 1991 Feb;23(1 Pt 2):1538-40.

10. Baccarani U, Isola M, Adani GL, Avellini C, Lorenzin D, Rossetto A, et al. Steatosis of the hepatic graft as a risk factor for post-transplant biliary complications. Clinical Transplantation. 2010 Sep;24(5):631-5.

11. Mccormack L, Petrowsky H, Jochum W, Mullhaupt B, Weber M, Clavien P-A. Use of severely steatotic grafts in liver transplantation: a matched case-control study. Ann Surg. 2007 Dec;246(6):940-6-discussion946-8.

12. Spitzer AL, Lao OB, Dick AAS, Bakthavatsalam R, Halldorson JB, Yeh MM, et al. The biopsied donor liver: incorporating macrosteatosis into high-risk donor assessment. Liver Transpl. 2010 Jul;16(7):874-84.

13. Jamieson RW, Zilvetti M, Roy D, Hughes D, Morovat A, Coussios CC, et al. Hepatic steatosis and normothermic perfusion-preliminary experiments in a porcine model. Transplantation. 2011 Aug 15;92(3):289-95. 
14. Nagrath D, Xu H, Tanimura Y, Zuo R, Berthiaume F, Avila M, et al. Metabolic preconditioning of donor organs: defatting fatty livers by normothermic perfusion ex vivo. Metab Eng. 2009 Jul;11(4-5):274-83.

15. Ureña MA, Ruiz-Delgado FC, González EM, Segurola CL, Romero CJ, García IG, et al. Assessing risk of the use of livers with macro and microsteatosis in a liver transplant program. Transplant Proc. 1998 Nov;30(7):3288-91.

16. Nocito A, El-Badry AM, Clavien P-A. When is steatosis too much for transplantation? J Hepatol. 2006 Oct;45(4):494-9.

17. Schwenzer NF, Springer F, Schraml C, Stefan N, Machann J, Schick F. Non-invasive assessment and quantification of liver steatosis by ultrasound, computed tomography and magnetic resonance. J Hepatol. 2009 Sep;51(3):433-45.

18. Hernaez R, Lazo M, Bonekamp S, Kamel I, Brancati FL, Guallar E, et al. Diagnostic accuracy and reliability of ultrasonography for the detection of fatty liver: a metaanalysis. Hepatology. 2011 Sep 2;54(3):1082-90.

19. Park SH, Kim PN, Kim KW, Lee SW, Yoon SE, Park SW, et al. Macrovesicular hepatic steatosis in living liver donors: use of CT for quantitative and qualitative assessment. Radiology. 2006 Apr;239(1):105-12.

20. Rogier J, Roullet S, Cornélis F, Biais M, Quinart A, Revel P, et al. Noninvasive assessment of macrovesicular liver steatosis in cadaveric donors based on computed tomography liver-to-spleen attenuation ratio. Liver Transpl. 2015 May;21(5):690-5.

21. Zheng D, Guo Z, Schroder PM, Zheng Z, Lu Y, Gu J, et al. Accuracy of MR Imaging and MR Spectroscopy for Detection and Quantification of Hepatic Steatosis in Living Liver Donors: A Meta-Analysis. Radiology. 2017 Jan;282(1):92-102.

22. Bohte AE, van Werven JR, Bipat S, Stoker J. The diagnostic accuracy of US, CT, MRI and 1H-MRS for the evaluation of hepatic steatosis compared with liver biopsy: a meta-analysis. Eur Radiol. 2011 Jan;21(1):87-97.

23. Sasso M, Beaugrand M, de Ledinghen V, Douvin C, Marcellin P, Poupon R, et al. Controlled attenuation parameter (CAP): a novel VCTETM guided ultrasonic attenuation measurement for the evaluation of hepatic steatosis: preliminary study and validation in a cohort of patients with chronic liver disease from various causes. Ultrasound Med Biol. 2010 Nov;36(11):1825-35.

24. Rey JW, Wirges U, Dienes HP, Fries JWU. Hepatic steatosis in organ donors: disparity between surgery and histology? Transplant Proc. 2009 Jul;41(6):2557-60.

25. Yersiz H, Lee C, Kaldas FM, Hong JC, Rana A, Schnickel GT, et al. Assessment of hepatic steatosis by transplant surgeon and expert pathologist: A prospective, doubleblind evaluation of 201 donor livers. Liver Transpl. 2013 Mar 17;19(4):437-49.

26. Lo IJ, Lefkowitch JH, Feirt N, Alkofer B, Kin C, Samstein B, et al. Utility of liver allograft biopsy obtained at procurement. Liver Transpl. 2008 May;14(5):639-46. 
27. Le Naour F, Bralet M-P, Debois D, Sandt C, Guettier C, Dumas P, et al. Chemical imaging on liver steatosis using synchrotron infrared and ToF-SIMS microspectroscopies. PLoS ONE. 2009 Oct 12;4(10):e7408.

28. Le Naour F, Gadea L, Danulot M, Yousef I, Vibert E, Wavelet M, et al. Quantitative assessment of liver steatosis on tissue section using infrared spectroscopy. Gastroenterology. 2015 Feb;148(2):295-7.

29. Peng C, Chiappini F, Kaščáková S, Danulot M, Sandt C, Samuel D, et al. Vibrational signatures to discriminate liver steatosis grades. Analyst. The Royal Society of Chemistry; 2015 Feb 21;140(4):1107-18.

30. Evers DJ, Westerkamp AC, Spliethoff JW, Pully VV, Hompes D, Hendriks BHW, et al. Diffuse reflectance spectroscopy: toward real-time quantification of steatosis in liver. Transpl Int. 2015 Apr;28(4):465-74.

31. Westerkamp AC, Pully VV, Karimian G, Bomfati F, Veldhuis ZJ, Wiersema-Buist J, et al. Diffuse reflectance spectroscopy accurately quantifies various degrees of liver steatosis in murine models of fatty liver disease. J Transl Med. 2015 Sep 21;13(1):309.

32. Marsman H, Matsushita T, Dierkhising R, Kremers W, Rosen C, Burgart L, et al. Assessment of donor liver steatosis: pathologist or automated software? Human Pathology. 2004 Apr;35(4):430-5.

33. Fiorini RN, Kirtz J, Periyasamy B, Evans Z, Haines JK, Cheng G, et al. Development of an unbiased method for the estimation of liver steatosis. Clinical Transplantation. 2004 Dec;18(6):700-6.

34. El-Badry AM, Breitenstein S, Jochum W, Washington K, Paradis V, Rubbia-Brandt L, et al. Assessment of hepatic steatosis by expert pathologists: the end of a gold standard. Ann Surg. 2009 Nov;250(5):691-7.

35. Kulik U, Lehner F, Klempnauer J, Borlak J. Primary non-function is frequently associated with fatty liver allografts and high mortality after re-transplantation. Liver Int. 2017 Mar 7.

36. Adani GL, Baccarani U, Sainz-Barriga M, Lorenzin D, Bresadola V, Risaliti A, et al. The role of hepatic biopsy to detect macrovacuolar steatosis during liver procurement. Transplant Proc. 2006 Jun;38(5):1404-6.

37. Barbois S, Arvieux C, Leroy V, Reche F, Sturm N, Borel A-L. Benefit-risk of intraoperative liver biopsy during bariatric surgery: review and perspectives. Surg Obes Relat Dis. 2017 Oct;13(10):1780-6.

38. Cucchetti A, Vivarelli M, Ravaioli M, Cescon M, Ercolani G, Piscaglia F, et al. Assessment of donor steatosis in liver transplantation: is it possible without liver biopsy? Clinical Transplantation. 2009 Aug;23(4):519-24.

39. Stern C, Castera L. Non-invasive diagnosis of hepatic steatosis. Hepatol Int. Springer India; 2017 Jan;11(1):70-8. 
40. Cesaretti M, Poté N, Dondero F, Cauchy F, Schneck AS, Soubrane O, et al. Testing feasibility of an accurate microscopic assessment of macrovesicular steatosis in liver allograft biopsies by smartphone add-on lenses. Microsc Res Tech. 2017 Oct 17.

41. Cesaretti M, Poté N, Cauchy F, Dondero F, Dokmak S, Sepulveda A, et al. Noninvasive assessment of liver steatosis in deceased donors: A pilot study. Liver Transpl. 2017 Dec 22.

42. Frankel WL, Tranovich JG, Salter L, Bumgardner G, Baker P. The optimal number of donor biopsy sites to evaluate liver histology for transplantation. Liver Transpl. W.B. Saunders; 2002 Nov;8(11):1044-50.

43. Ratziu V, Charlotte F, Heurtier A, Gombert S, Giral P, Bruckert E, et al. Sampling variability of liver biopsy in nonalcoholic fatty liver disease. Gastroenterology. 2005 Jun;128(7):1898-906.

44. Imber CJ, St Peter SD, Lopez I, Guiver L, Friend PJ. Current practice regarding the use of fatty livers: a trans-Atlantic survey. Liver Transpl. W.B. Saunders; 2002 Jun;8(6):545-9.

45. Wilson CB. Adoption of new surgical technology. BMJ. 2006 Jan 14;332(7533):112-4.

46. Nasralla D, Coussios CC, Mergental H, Akhtar MZ, Butler AJ, Ceresa CDL, et al. A randomized trial of normothermic preservation in liver transplantation. Nature. Springer US; 2018 Apr 10;:1-23.

47. Li J, Liu B, Yan LN, Zuo YX, Li B, Zeng Y, et al. Reversal of graft steatosis after liver transplantation: prospective study. Transplant Proc. 2009 Nov;41(9):3560-3. 


\begin{tabular}{|c|c|c|c|}
\hline & $\begin{array}{c}\text { Stage } 1 \text {, before } \\
\text { selection } \\
n=67\end{array}$ & $\begin{array}{c}\text { Stage } 1 \text {, after } \\
\text { selection } \\
n=35\end{array}$ & $\begin{array}{c}\text { Stage } 2 \\
n=154\end{array}$ \\
\hline Age & $55.6 \pm 17$ & $57 \pm 18$ & $58.1 \pm 19$ \\
\hline Male/Female (\%) & 35 (53.7) / 31 (46.3) & $\begin{array}{c}19(54.3) / \\
16(45.7)\end{array}$ & $\begin{array}{c}73(47.4) / \\
81(52.6)\end{array}$ \\
\hline BMI $\left(\mathrm{kg} / \mathrm{m}^{2}\right)$ & $24.8 \pm 5$ & $25.5 \pm 4.5$ & $26.4 \pm 6.3$ \\
\hline $\begin{array}{c}\text { Alcohol consumption, } \\
\text { n (\%) }\end{array}$ & $11(16.4)$ & $5(14.3)$ & $26(16.8)$ \\
\hline Max. liver height (mm) & $161 \pm 29$ & $163 \pm 25$ & $159 \pm 25$ \\
\hline Liver weight* (g) & $1380 \pm 416$ & $1342 \pm 432$ & $1381 \pm 334$ \\
\hline $\begin{array}{c}\text { Liver/Spleen attenuation } \\
\text { ratio* }\end{array}$ & $1.33 \pm 0.57$ & $1.33 \pm 0.57$ & $1.24 \pm 0.59$ \\
\hline $\begin{array}{c}\text { METAVIR fibrosis score } \\
\text { F0/F1/F2/F3/F4 (\%) }\end{array}$ & $47.8 / 26.9 / 3 / 7.4 / 14.9$ & $71.4 / 25.7 / 2.9 / 0 / 0$ & $75 / 22.5 / 2.5 / 0 / 0$ \\
\hline $\begin{array}{c}\text { Scans in LT setting vs } \\
\text { elective liver surgery, } \mathrm{n} \\
(\%)\end{array}$ & $43(64.2) / 24(35.8)$ & $35(100) / 0(0)$ & $\begin{array}{c}138(89.6) / \\
16(10.4)\end{array}$ \\
\hline $\begin{array}{l}\text { If } \mathrm{LT}, \text { scan in donor vs } \\
\text { recipient, } \mathbf{n}(\%)\end{array}$ & $18(41.9) / 25(58.1)$ & $13(37.1)$ & $\begin{array}{c}83(60.1) / \\
55(39.9)\end{array}$ \\
\hline $\begin{array}{c}\text { HBV or HCV carriers, } \\
\text { n (\%) }\end{array}$ & $11(16.4)$ & $2(5.7)$ & $4(2.6)$ \\
\hline $\begin{array}{c}\text { Percentage of } \\
\text { Macrosteatosis } \\
\text { Mean/Median/SD }\end{array}$ & $9.3 / 5$ / 13.1 & $7.5 / 2 / 12.6$ & $6 / 2 / 9.9$ \\
\hline $\begin{array}{c}\text { Percentage of } \\
\text { Microsteatosis } \\
\text { Mean/Median/SD }\end{array}$ & $9.2 / 5 / 12.4$ & $11.5 / 5$ / 13.9 & $9 / 0 / 13.3$ \\
\hline
\end{tabular}

Table 1: Epidemiological, radiological, clinical and pathological features of the livers scanned during stages 1 (calibration cohort) and 2 (validation cohort)

*: data only available for liver grafts; SD: standard deviation; LT: liver transplantation 


\begin{tabular}{c|cccc}
\hline Variable & pc & 95\% confident interval & P value \\
\hline Calculated macro-steatosis & 0.78 & $0.73-0.83$ & $<0.0001$ \\
Body mass index* & 0.28 & $0.13-0.42$ & 0.0005 \\
Liver weight & 0.25 & $0.08-0.41$ & 0.005 \\
Liver height* & 0.02 & $-0.15-0.19$ & 0.85 \\
Liver-to-spleen attenuation ratio* & -0.11 & $-0.29-0.07$ & 0.23 \\
\hline
\end{tabular}

Table 2: Correlation between the pathological assessment of macrosteatosis, spectrometer results and perioperative features (validation cohort)

*: data provided by the French Agency of Biomedicine; $\rho c$ : Lin's concordance correlation coefficient 


\section{LEGENDS}

Fig 1: Intraoperative view showing the spectrometer near the Glisson capsule and communicating with a smartphone via Bluetooth connexion.

Fig 2: Flow chart of the present study.

Fig 3: Testing of the model on the whole cohort $(A, n=67)$ or after selection $(B, n=35)$ during stage 1.

Fig 4: Liver scans during stage 1. The analysis was restricted to wavelengths between $895 \mathrm{~nm}$ and $945 \mathrm{~nm}$.

Fig 5: Correlations between the pathological MS analysis and the estimated MS. (Validation cohort) 


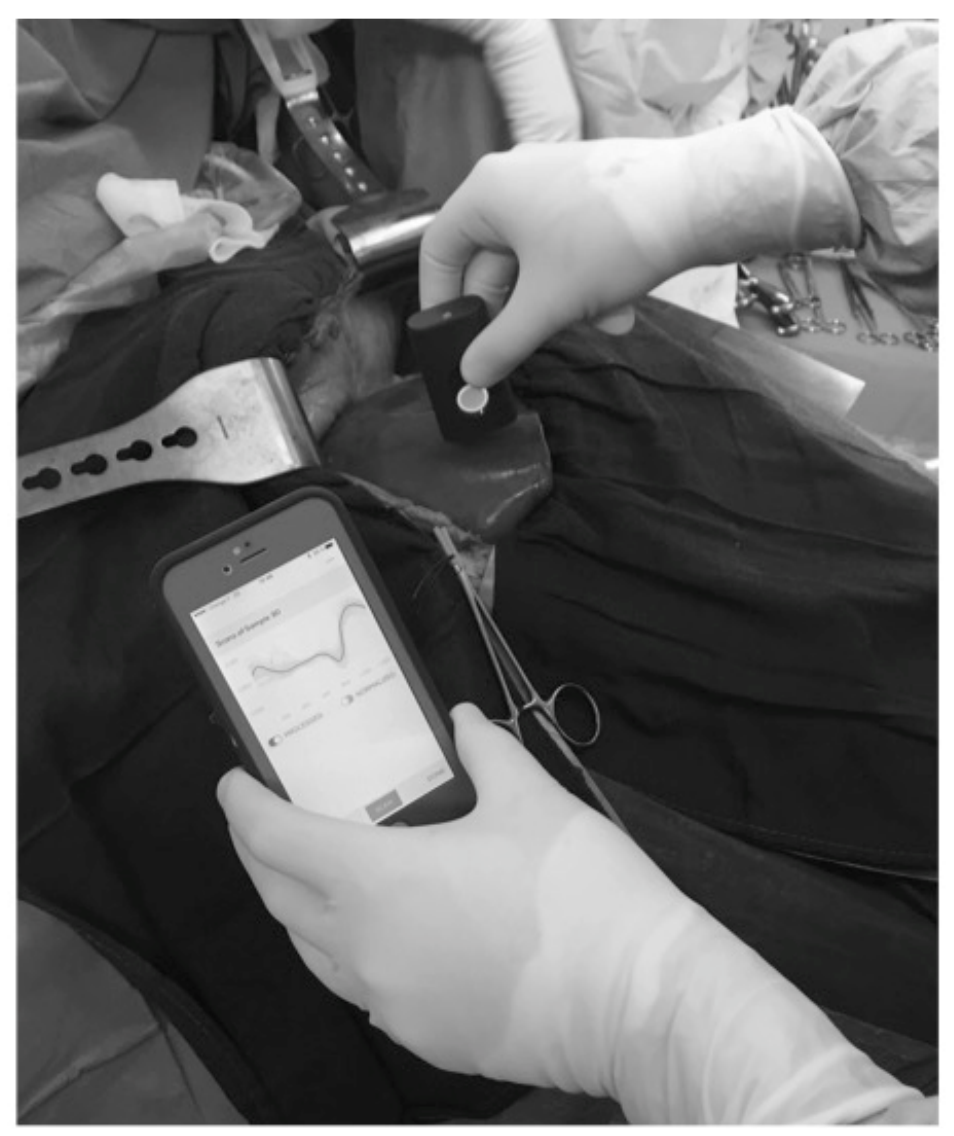

Fig 1 


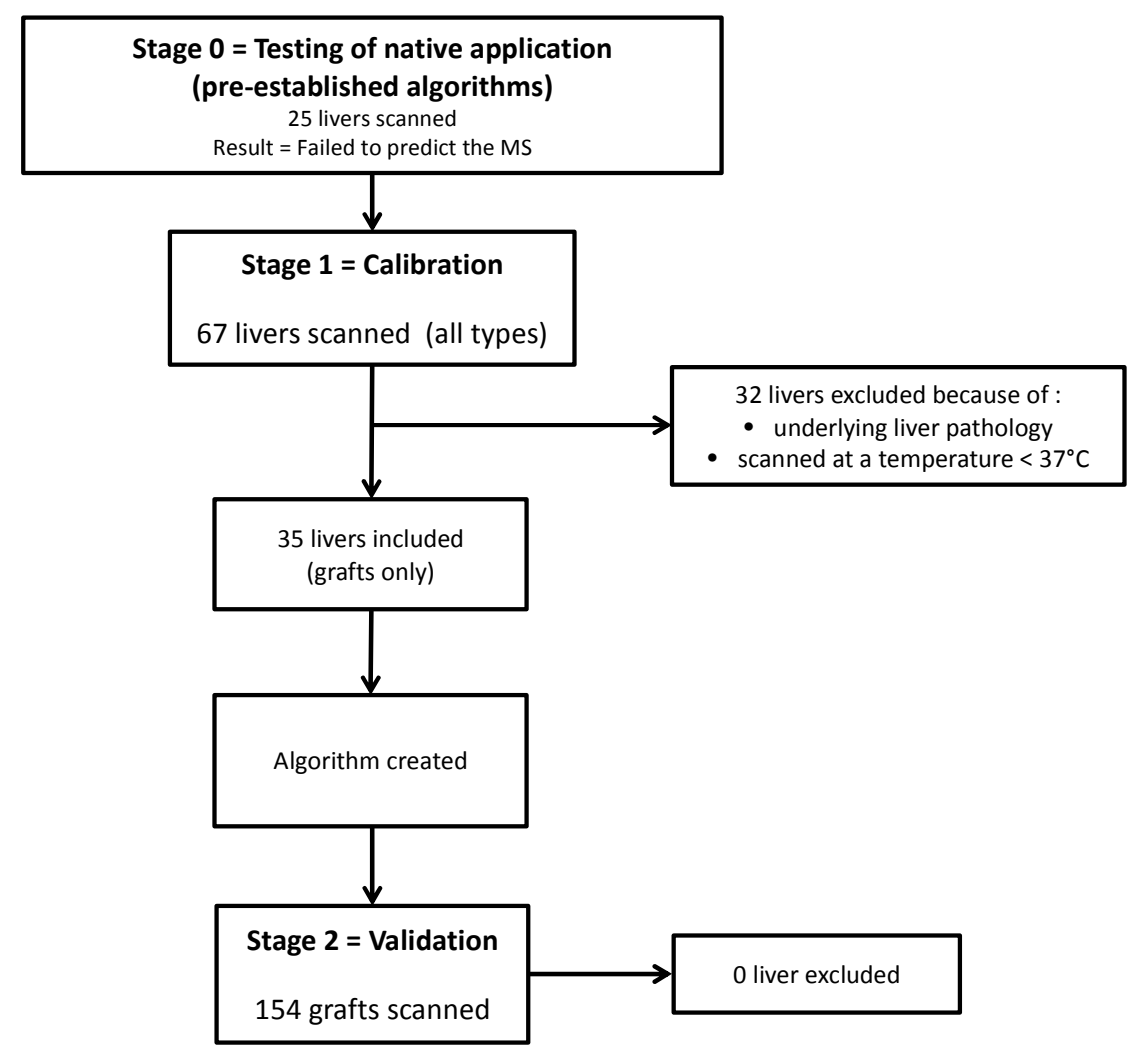

Fig 2 

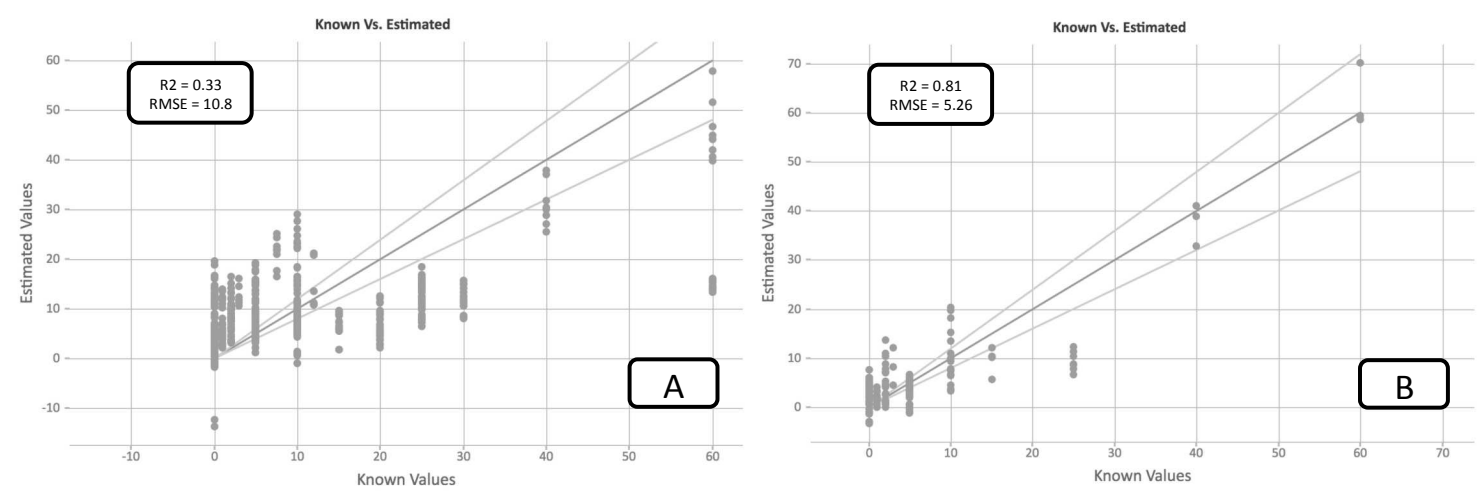

Fig 3 


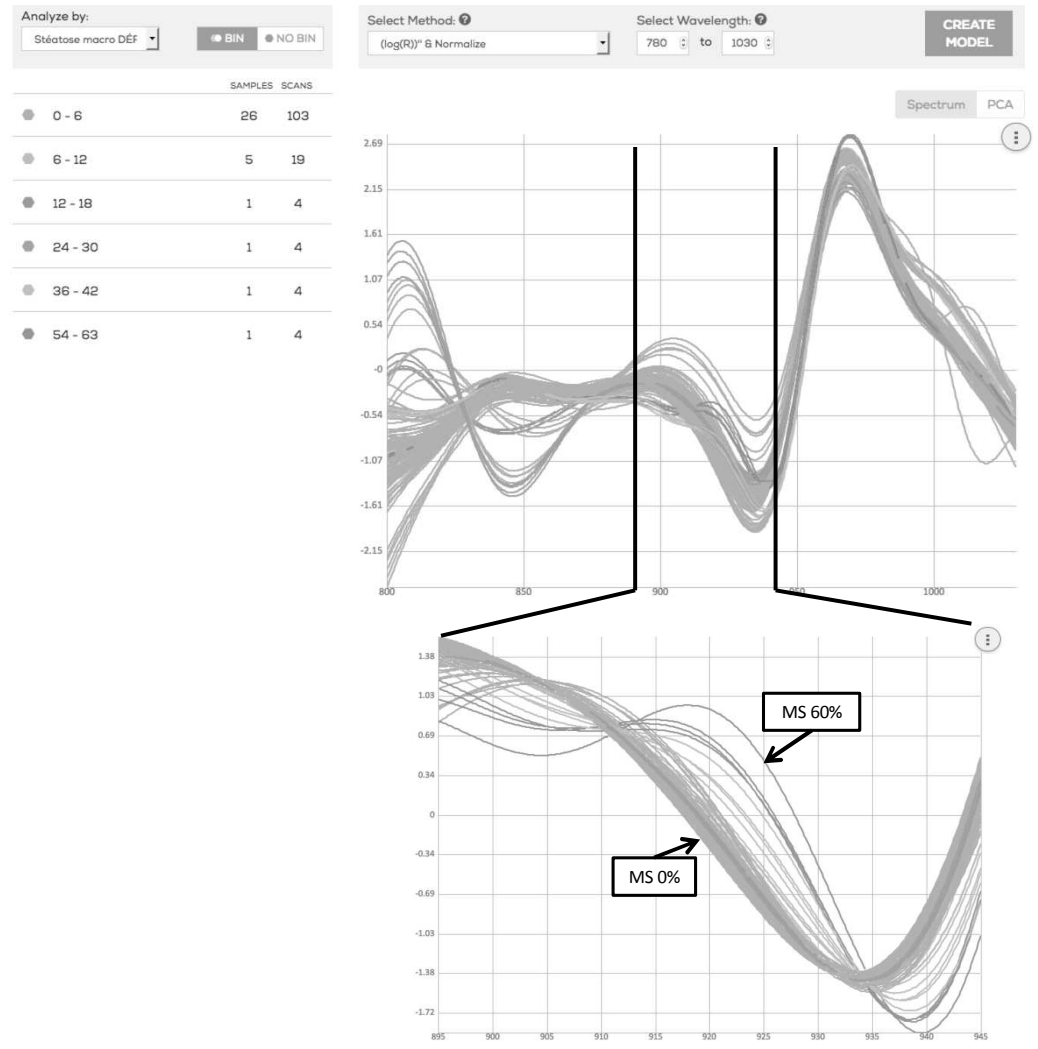

Spectra from the 35 selected livers during stage 1

Fig 4 


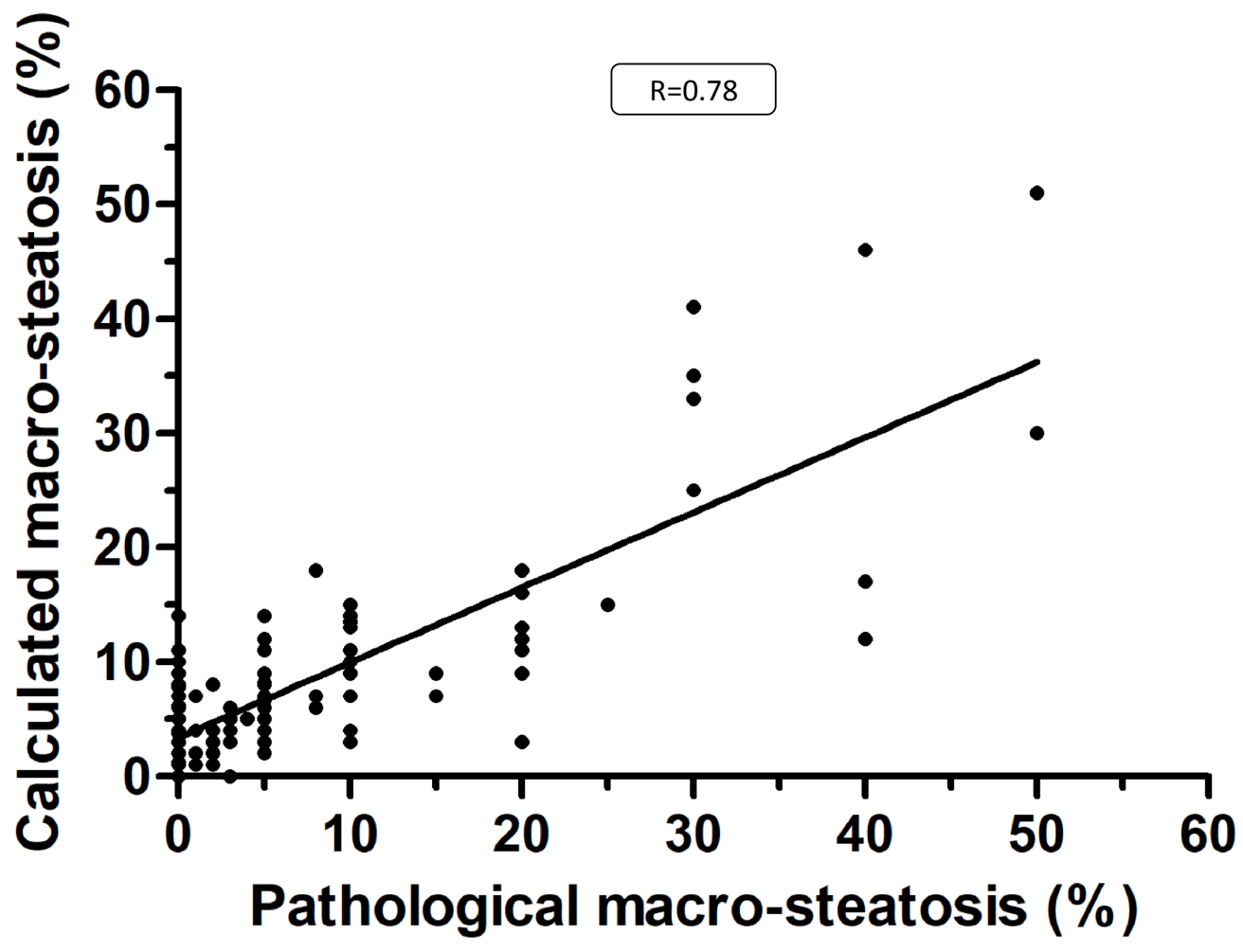

Fig 5 
